\title{
The Improvement of the Design Standard of Overloaded Highway
}

\author{
Dou Yuanming, Zhang Jingjing and $\mathrm{Hu}$ Chao \\ Hebei University of Technology, Tianjin, China \\ 15022741875@163.com
}

\begin{abstract}
With the development of the transportation industry, the trend of overload is obviously, design load of highway bridges needs to be improved. Based on the field investigation and data analysis, this study modifies the design standers of highway. The regularities on characteristics of models, vehicle weight and the distribution of axle load and spacing were studied. Using the Matlab programming language and the Monte Carlo numerical simulation method to simulate a random traffic model, then loaded on simple bridges and continuous bridges with different span in order to calculate bending effect. The data were compared with the first level in highway load code and proposed the load increase parameters: when the span is less than $20 \mathrm{~m}$, then use 1.2 times the standard specification in bridge design; in other situation, use 1.3 times the standard factor. Analyzing the characteristic of the vehicle load, can not only give technical parameters for the quantitative analysis of overloading traffic effects on the fatigue damage of bridge, but also provide a reference for bridge design units and the operation management department. So it has great realistic significance and research value.
\end{abstract}

Keywords: overload highway, load spectrum, highway code, increase parameters

\section{Introduction}

With the rapid development of China's economy, transport requirement by Highway Bridges is increasing, the trend that vehicles are heavier and large-scale is obvious. As the costs for vehicle operation are increasing and some managers are driven by the profit, overload has become normal. This situation happens frequently and the gross weight and axle load of the vehicles are huge. If the design standard and the actual situation are not unified mutually, there may be safe and economic problems in bridge engineering, then the loss of social wealth will be incalculable[1]. In this issue calculated the actual vehicle load effect, and compared with the first level in highway load code[2] and proposed the load increase factor, aiming to do a quantitative analysis on the influence for bridge structure under overloaded traffic, providing technical parameters in the design scheme and also giving technical references for both the design unit and the bridges' management departments.

Cai Jiaming[3] used the optimal fitting method based on the K - S in 2006 to analyze the vehicle load distribution of the important road in rush hours; Through the actual traffic survey in 2007, Wang Shuo[4], etc analyzed the basic vehicle load parameters of a typical bridge in Shanghai, and using Monte Carlo method to simulate the model to evaluate the reliability of bridge structure; Chen Min[5], etc in 2008 used the fixed dynamic weighing system for highway toll to collect the traffic data, then analyzed the vehicle load distribution, and put forward that the parameters of the vehicle weight and the distribution of flow, is irrelevant, which is helpful to establish a vehicle load spectrum; Guo Tong[6], etc carried out a statistical analysis and found that the vehicle load obey the distribution with extreme value I and the multi-peak distribution, then fitting the probability distribution of the vehicle load. And they used the compound poisson distribution and the 
compound weibull distribution to simulate the vehicle load in general and intensive operation condition.

Gindy[7] of some a bridge in New Jersey of USA in 2004, then calculated the maximum bending moment and the shear effect of the bridge, and put forward two kinds of extreme value prediction model; O'connor[8] in 2005 used the mobile weighing system called WIM to statistic the vehicle and the axle load, then analyzed the meaning of the basic parameters. They also evaluated the accuracy of the data to assess the reliability of the existing bridge structure.

Through the above study found that both at home and abroad, random study of vehicle load is divided into three stages: theoretical simulation analysis, the static structural vehicle load and the simulation of the actual traffic load. The present survey of the vehicle load model is restricted in our country, so it has no universality and representativeness. To study the characteristics of the vehicle load, a statistical analysis and simulation are necessary, in this paper, on the basis of the experience, the further research is conducted to improve the shortcomings.

\section{Traffic Statistics}

This paper place the emphasis on the vehicle load in highway and bridge under overloaded traffic, and based on a large number of survey and analysis, we choose two representative sections: the southern section of Daqing-Guangzhou highway in Gu'an and the northern section of Beijing-Zhuhai highway in Zhuozhou. These two sections are the north-south direction and run through Hebei Province, also they are important channels going to Beijing. There are more overloaded trucks and the load characteristics are typical. And the southern section of Daqing-Guangzhou highway in Gu'an is in expansion from four lanes to six lanes, the study of traffic flow and vehicle load analysis provide a theoretical basis for the traffic prediction after reconstruction. Beijing-Zhuhai and Daqing-Guangzhou highway are the main traffic artery of the national from the north to south direction at the same time, the research about these two sections can not only provide technical parameters for vehicle load design countermeasures in our province, but also can provide technical reference for the nationwide. We collected 10371 data and statistics the road traffic distribution from the road traffic investigation in 24 hours. Due to heavy traffic loading conditions study, thus focuses on the freight $\mathrm{car}^{[9]}$. The truck models were divided into five types according to the numbers of axle, as 2-axle, 3-axle, 4 axle, 5-axle and 6-axle truck. The specific flow distribution is shown in Figure 1.

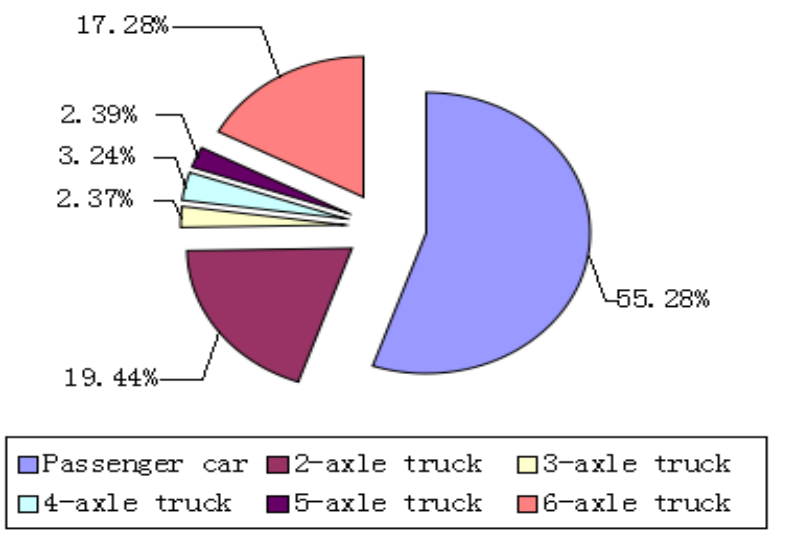

Figure 1. Models Proportion

To calculate the actual vehicle load effects of the bridge, there are three main variables need to be determined by investigation: the proportion of the distribution of each type of vehicle, typical vehicle axle's parameters and the vehicle spacing ${ }^{[10]}$. Through simulating 
the random process and analysing the data by Matlab software, we got the load distribution under random condition.

\section{Analysis of Typical Vehicles' Axle Parameters}

\subsection{The Wheelbase}

To calculate the equivalent wheelbase of each model of the load spectrum, the proportion that each type of vehicle with the total number of the same type of vehicle is treated as weights, then weighted the average of the wheelbase and statistics of its value.

$$
A_{j}=\sum_{i=1}^{n} f_{i} A_{i j}
$$

Where,

Aij is the jth wheelbase of the ith kind of the same vehicle.

fi is the ratio for the ith kind of vehicle compared with the total number of the same kind.

$\mathrm{Aj}$ is the equivalent wheelbase of the $\mathrm{j}$-th axle fin the model vehicle.

The calculation results as shown in table 1

Table 1. Equivalent Wheelbase

\begin{tabular}{ccccccc}
\hline $\begin{array}{c}\text { Axle } \\
\text { Category }\end{array}$ & $\begin{array}{c}\text { wheelbas } \\
\mathrm{e} 1\end{array}$ & $\begin{array}{c}\text { wheelbase } \\
2\end{array}$ & $\begin{array}{c}\text { wheelbas } \\
\mathrm{e} 3\end{array}$ & $\begin{array}{c}\text { wheelbase } \\
4\end{array}$ & $\begin{array}{c}\text { wheelbas } \\
\mathrm{e} 5\end{array}$ & ratio \\
\hline 2 axles & 4.0 & & & & & 0.436 \\
3 axles & 2.3 & 4.5 & & & & 0.051 \\
4 axles & 2.3 & 6.0 & 1.3 & & & 0.073 \\
5 axles & 3.5 & 6.3 & 2.0 & 1.3 & & 0.054 \\
6 axles & 2.6 & 2.0 & 7.0 & 1.35 & 1.35 & 0.386 \\
\hline
\end{tabular}

\subsection{The Vhicle Axle Load}

The axle load vary as different shaft types of the vehicle, then do the curve fitting as different axle types based on the survey of current vehicle load. Using vehicle weight of each model that was classified with higher frequency to do a bi-modal ${ }^{[11]}$ or three peak distribution of nonlinear fitting ${ }^{[12]}$. Rounding individual discrete large data, with a given significance level of 0.05 , and then test fitting situation. The results show that the vehicle weight distribution is not rejected multimodal distribution. After fitting of the curve, use the average as a typical vehicle axle load.

Table 2 Typical Vehicle Axle Load

\begin{tabular}{cccccccc}
\hline $\begin{array}{c}\text { Axle } \\
\text { Category }\end{array}$ & $\begin{array}{c}\text { wheelbas } \\
\text { e1 }\end{array}$ & $\begin{array}{c}\text { wheelbase } \\
2\end{array}$ & $\begin{array}{c}\text { wheelbas } \\
\text { e3 }\end{array}$ & $\begin{array}{c}\text { wheelbase } \\
4\end{array}$ & $\begin{array}{c}\text { wheelbase } \\
5\end{array}$ & $\begin{array}{c}\text { Wheelbas } \\
\text { e6 }\end{array}$ & ratio \\
\hline 2 axles & 45 & 100 & & & & & 0.436 \\
3 axles & 50 & 75 & 140 & & & & 0.051 \\
4 axles & 55 & 70 & 110 & 110 & & & 0.073 \\
5 axles & 55 & 125 & 100 & 100 & 100 & & 0.054 \\
6 axles & 55 & 95 & 115 & 105 & 105 & 105 & 0.386 \\
\hline
\end{tabular}

\subsection{The Vehicle Spacing in Load Spectrum}

Vehicle spacing is the distance between the two adjacent vehicles traveling on the road in the longitudinal direction. It various as the changing of time and speed. it's also an important parameter to statistic the overloading traffic impact and to make a typical load 
spectrum. In the paper, basing on the analysis target for trucks, the spacing was counted through a camera on-site to record the departure and arrival time of every truck. After sorting the data, then use the result to derive the vehicle spacing.

3.3.1 General Operating State: In the traffic survey, vehicle that measured are in the general state, with faster speed and the space between is larger. For the rest of samples fitting the logarithmic distribution, then verify they obey this distribution. The parameters are $^{\mu=4.7115}, \sigma=1.0702$

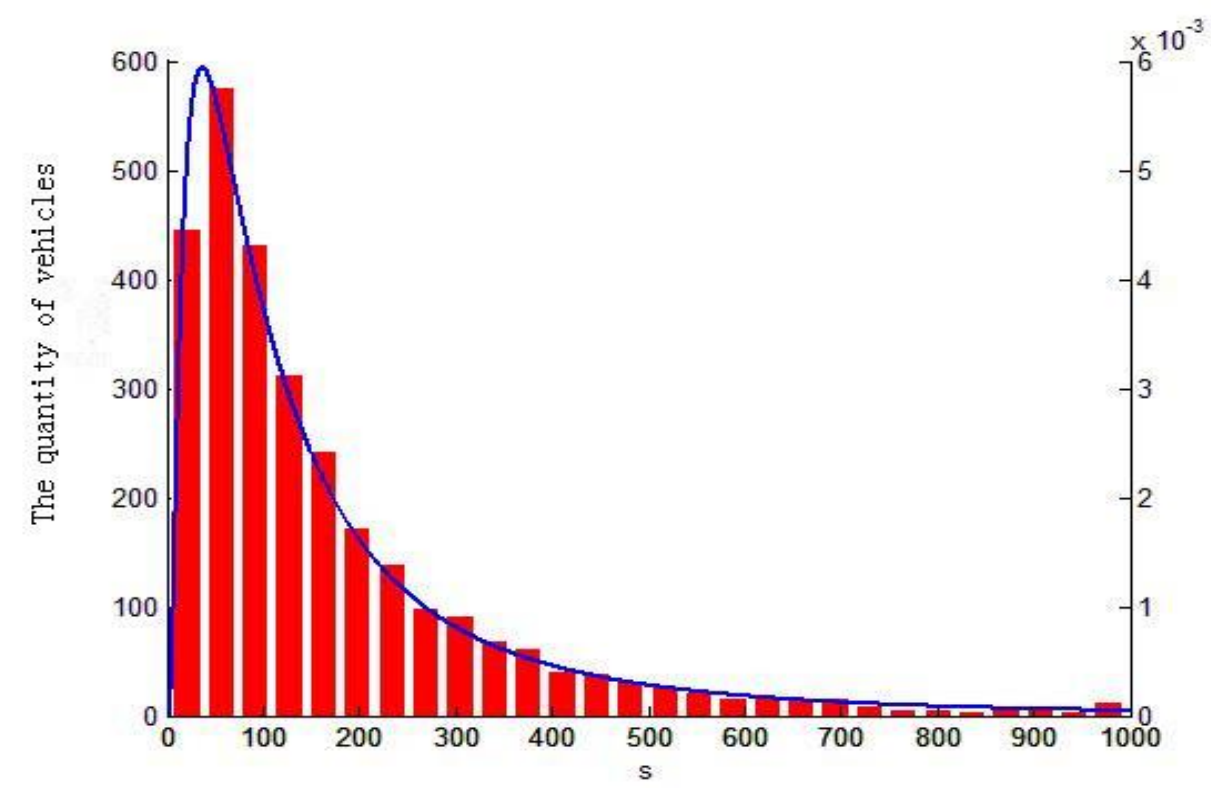

\section{Figure 2. The Fitting Figure of the Vehicle Spacing Under General Operating State}

3.3.2 Intensive Operating State: Without considering bus, the paper does analysis of the sample only for trucks. Based on the research of the traffic model, and referring to 2004 engineering structure reliability specifications, coming to a conclusion that under the intensive state the vehicle spacing obey to the logarithmic normal distribution. The parameters are ${ }^{\mu=1.561165}, \sigma=0.279707$

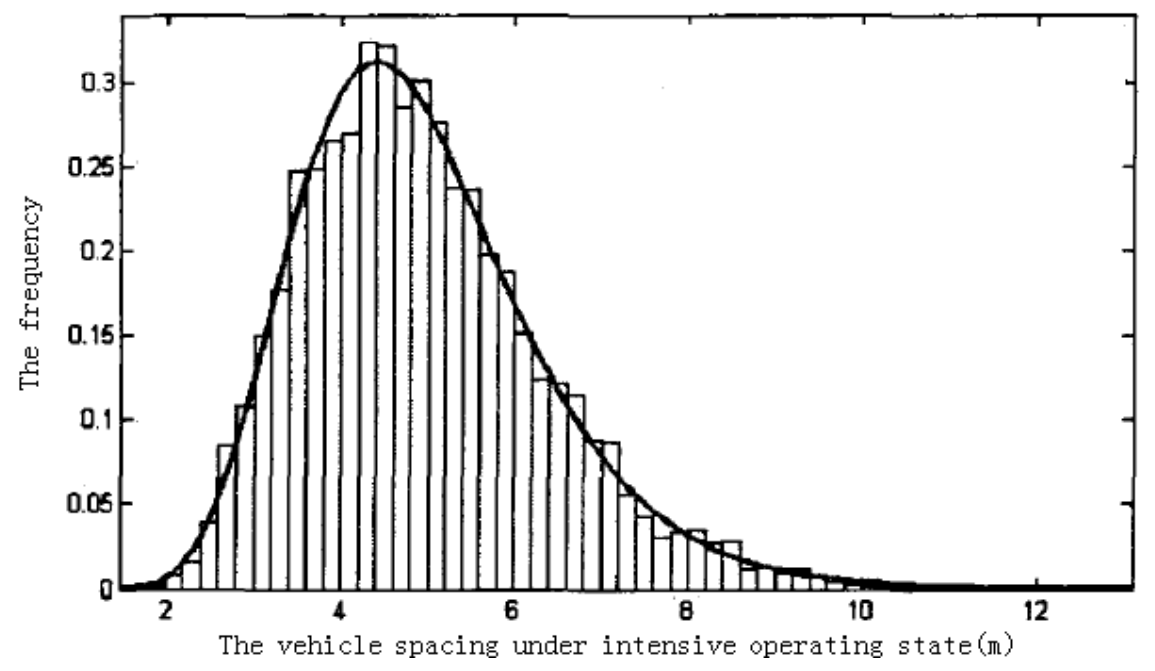

Figure 3. The Fitting Figure of the Vehicle Spacing under Intensive Operating State 


\section{Vehicle Load Effect}

Above are the distribution fitting to vehicle type, axle weight and vehicle spacing, but in the actual situation, directly for simulating vehicle load is very complex and difficult to control. Based on the analysis of flow patterns, the types, the weight and space are three factors as independent and random variables, then simplify the process of vehicle load spectrum model. Using Monte Carlo computer stochastic simulation method to establish a random vehicle load program and a randomly traffic flow model that generated obeys the law of the actual survey ${ }^{[13]}$. And then use the model to calculate the bending effect of bridge. Simulation process is illustrated in Figure 3.

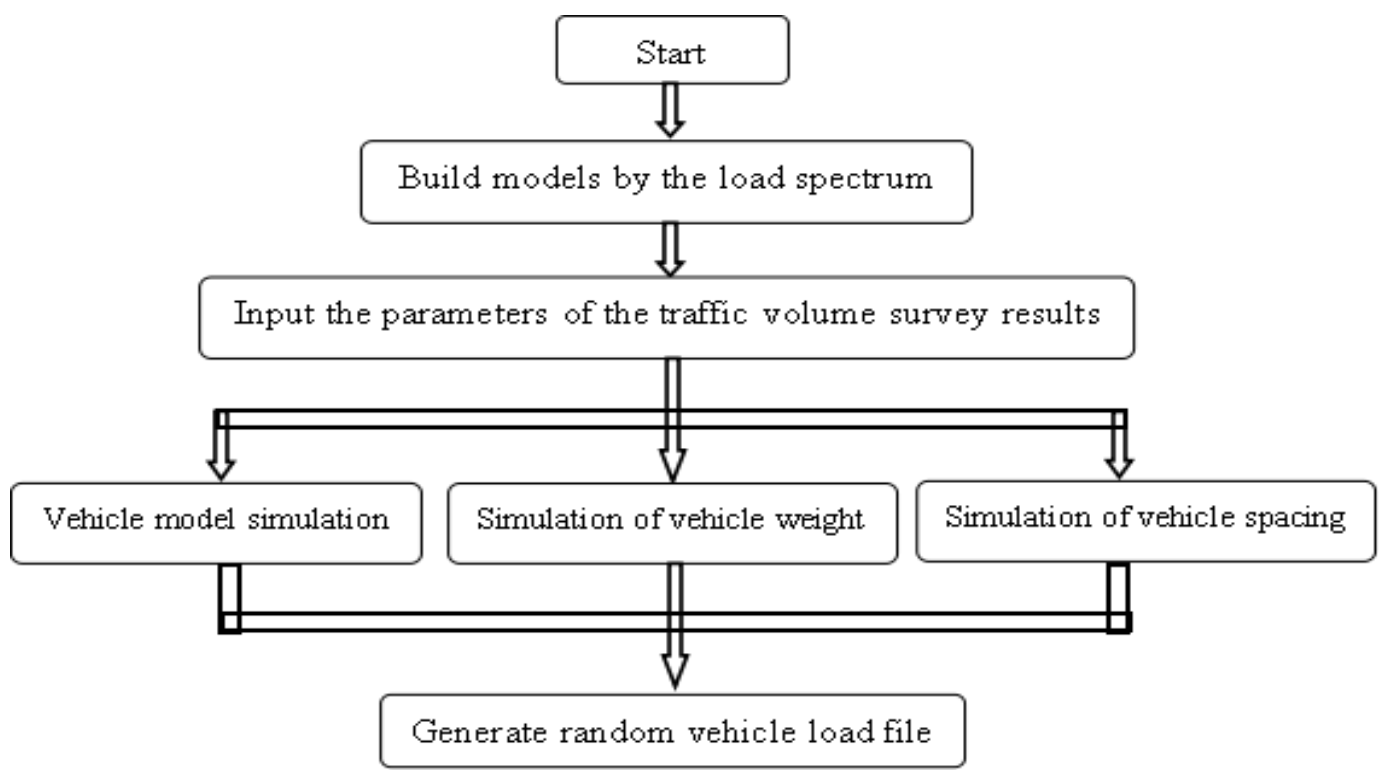

Figure 4. Random Vehicle Load Simulation Process

After generating a random traffic flow model, then using Matlab language to establish the load effect program based on the sample. The flow of random vehicle load was carried out on the bridge and to obtain load bending effect in the controlled section. From the theory about the influence line ${ }^{[14]}$, vehicle spacing is too large under normal operating state, often at the same time by only one vehicle through the bridge with smaller span, load effect produced is far less than under intensive state. So under the intensive vehicle operating state, carriers to $0.5 \mathrm{~m}$ in steps of a sample that goes through the bridge, and record every movement of the maximum bending effect. As showed in Figure 4. In order to choose, select $10 \mathrm{~m}, 15 \mathrm{~m}, 20 \mathrm{~m}, 25 \mathrm{~m}, 30 \mathrm{~m}, 35 \mathrm{~m}, 40 \mathrm{~m}, 50 \mathrm{~m}$ of simply supported girder bridge and 5-span continuous girder bridge (each span of $30 \mathrm{~m}$ ) as the sample ${ }^{[15]}$. The maximum bending moment distribution is shown in Figure 5 to 15 . The calculated bending moment compares with the first level in the highway load code. The result is shown in table 3. 


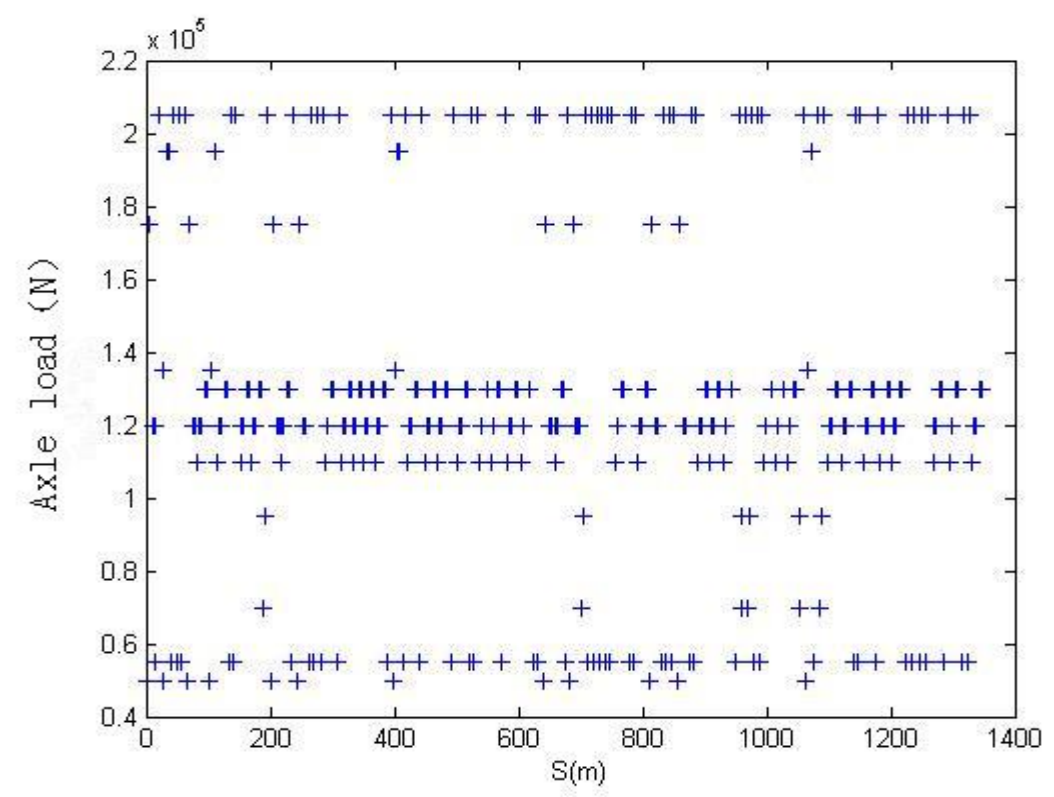

Figure 5.Random Traffic Loading Distribution Under Intensive Operating State

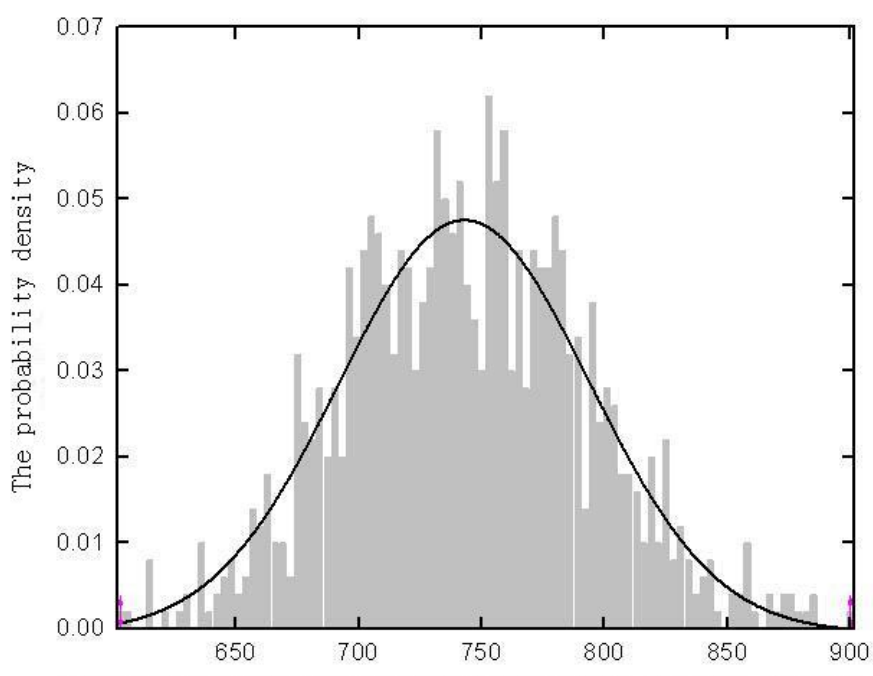

The maximum bending moment under random traffic $(\mathrm{KN} \cdot \mathrm{m})$

Figure 6. The Maximum Bending Moment of 10m Simple Beam Distribution 


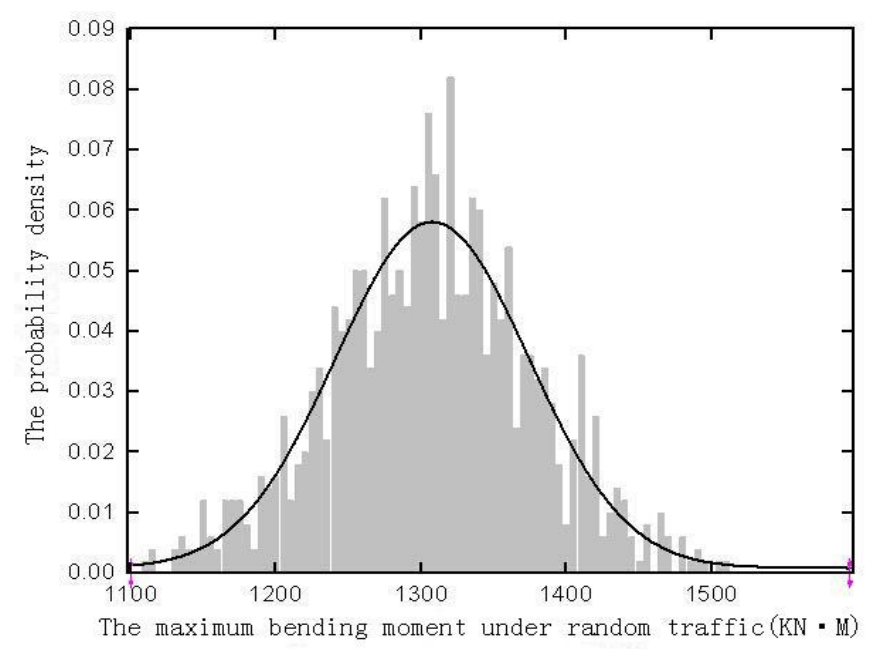

Figure 7. The Maximum Bending Moment of 15m Simple Beam Distribution

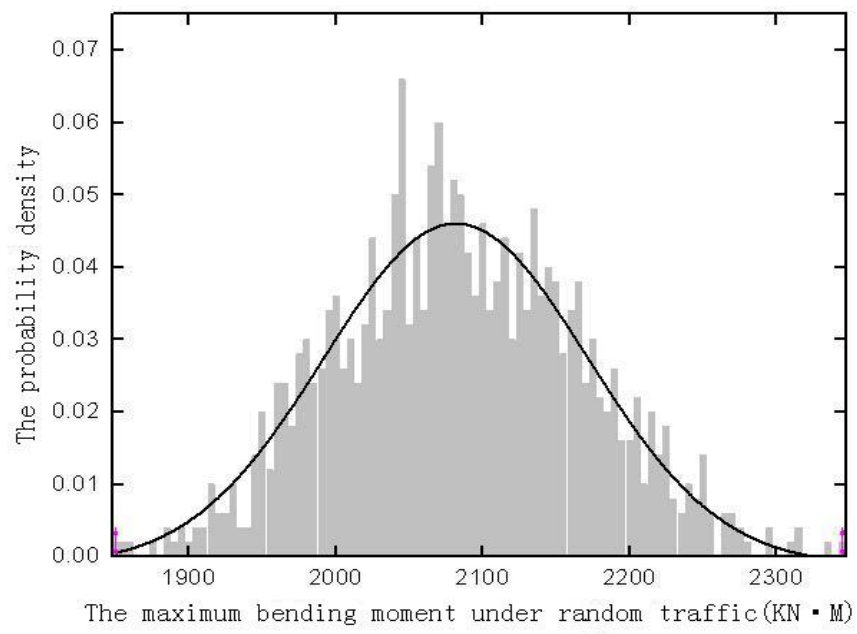

Figure 8. The Maximum Bending Moment of 20m Simple Beam Distribution

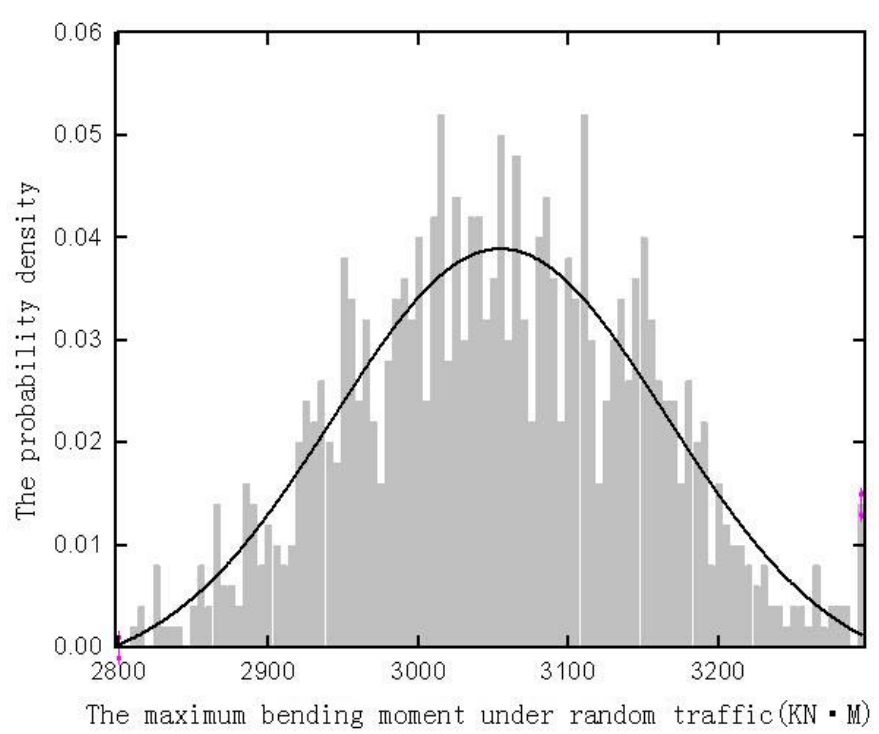

Figure 9. The Maximum Bending Moment of 25m Simple Beam Distribution 


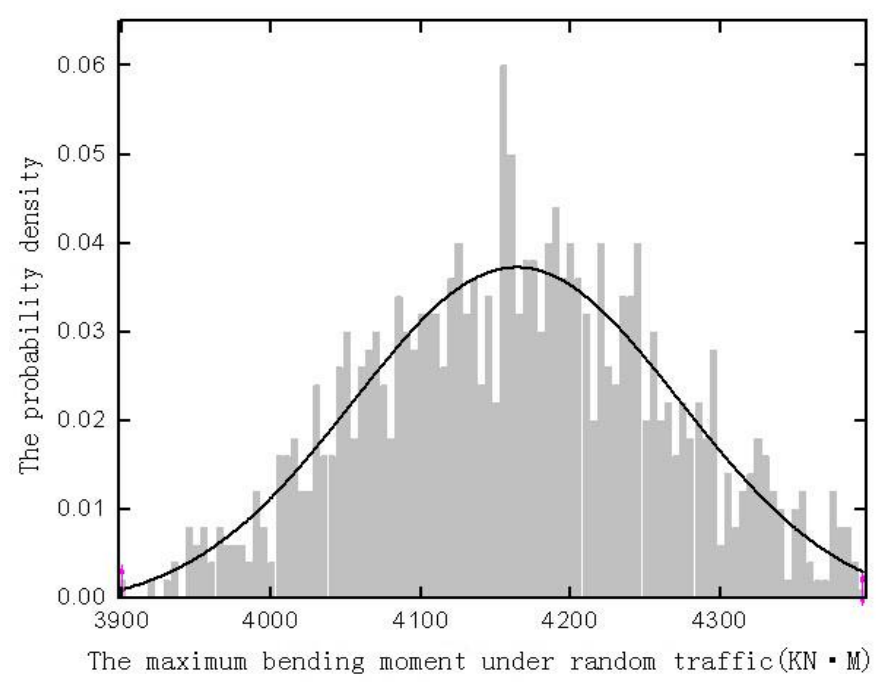

Figure 10. The Maximum Bending Moment of 30m Simple Beam Distribution

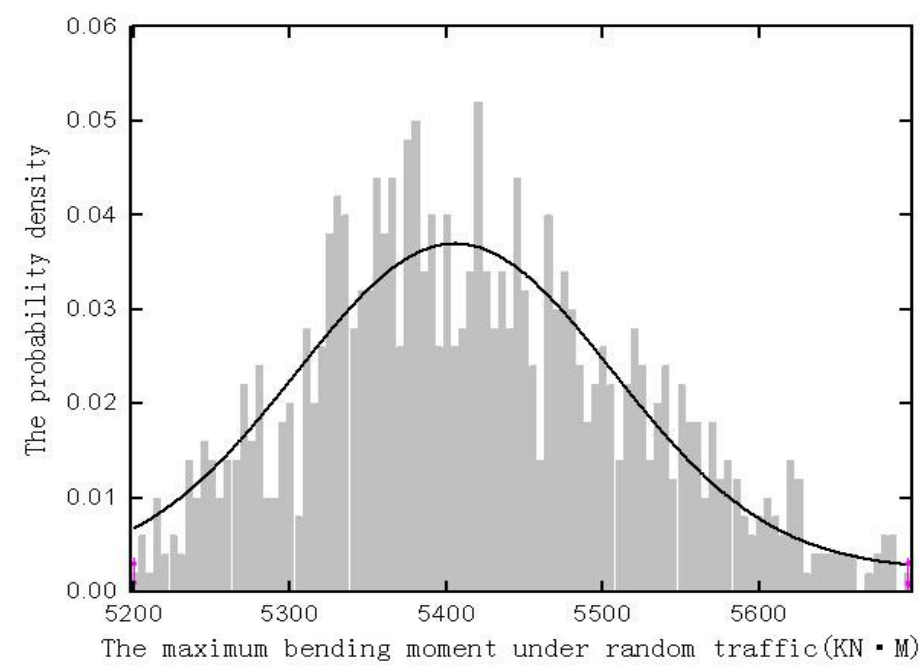

Figure 11. The Maximum Bending Moment of 35m Simple Beam Distribution

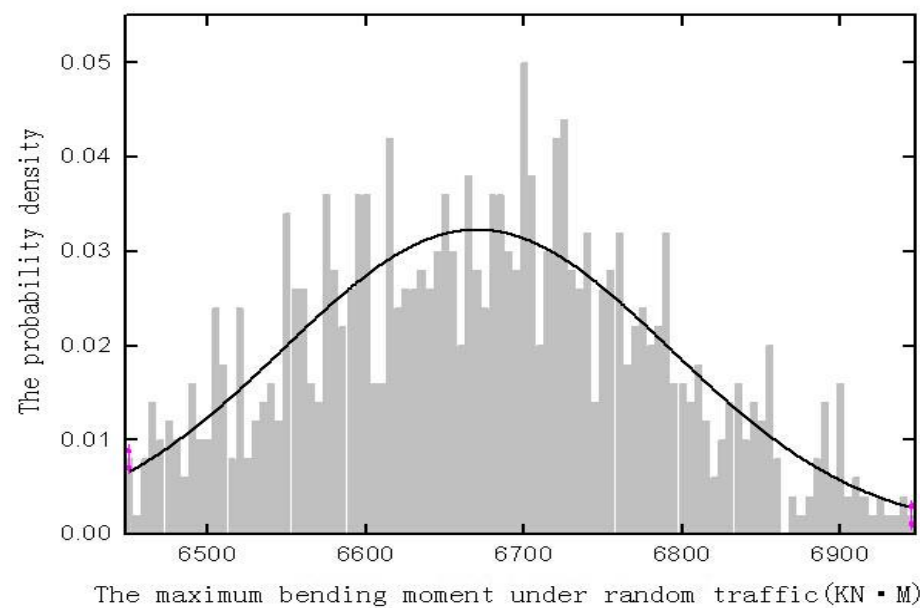

Figure 12. The maximum Bending Moment of $40 \mathrm{~m}$ Simple Beam Distribution 


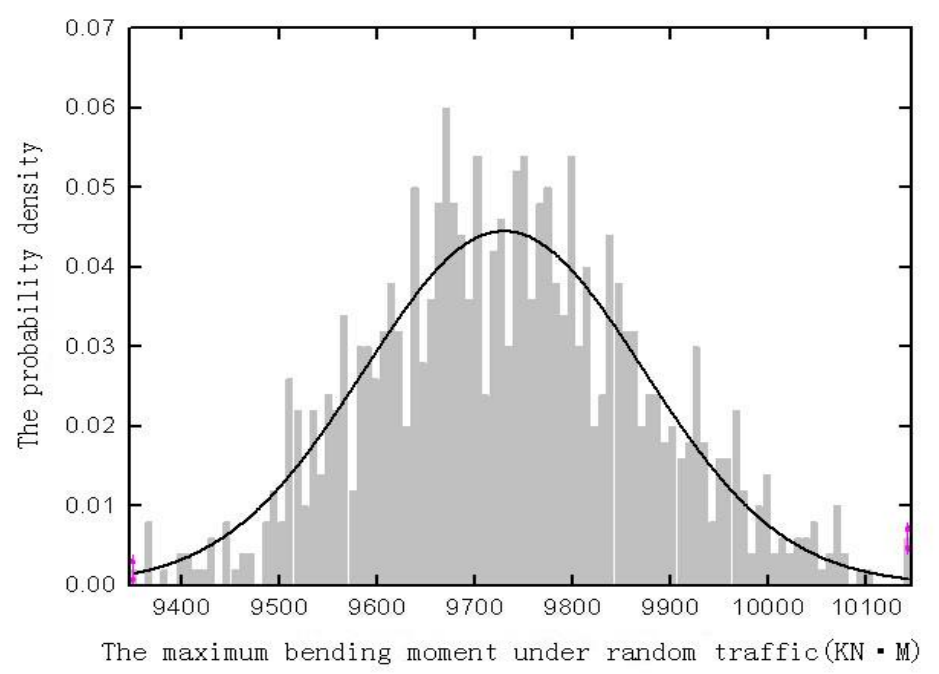

Figure 13. The Maximum Bending Moment of 50m Simple Beam Distribution

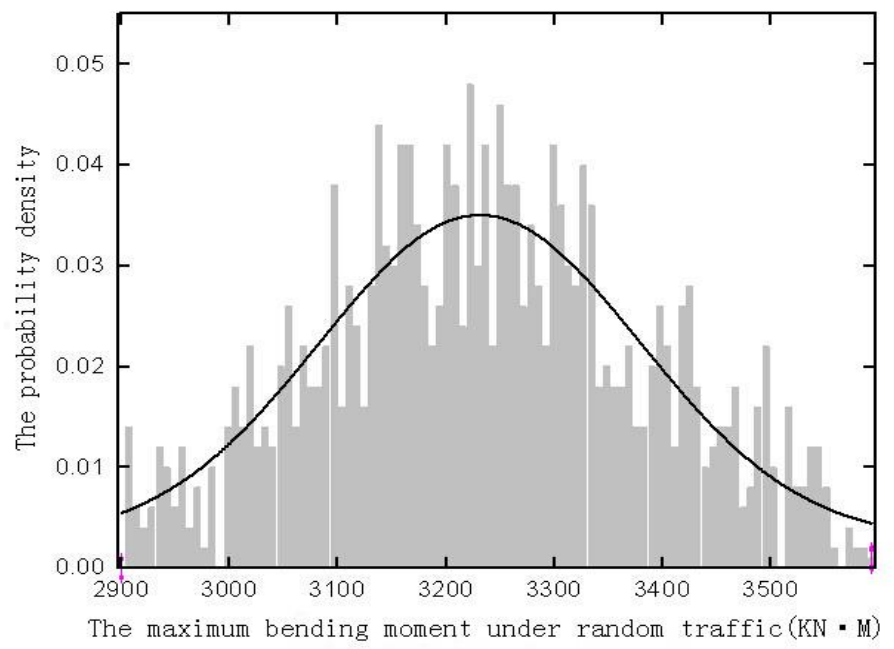

Figure 14. The Maximum Bending Moment Distribution of the Odd Number in $5 \times 3$ Across

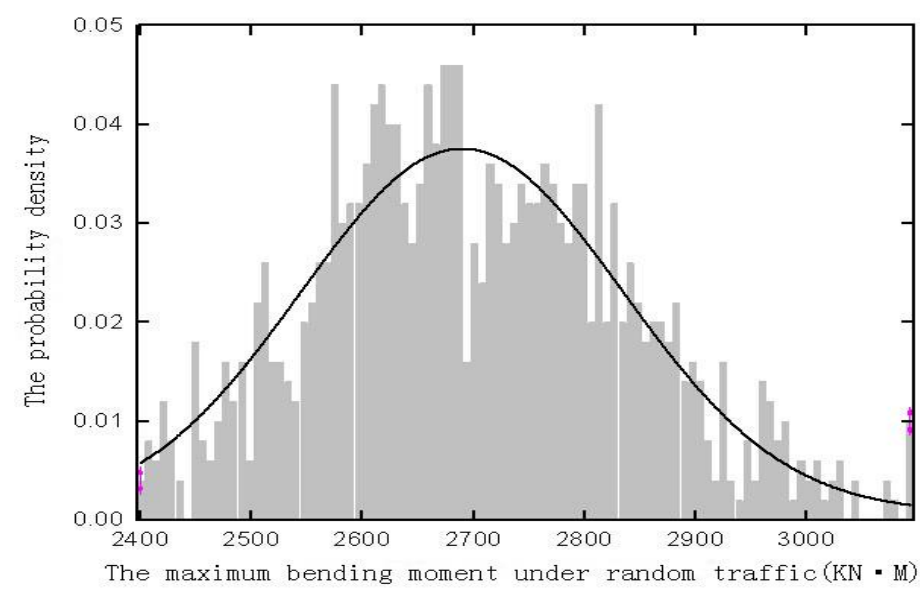

Figure 15. The Maximum Bending Moment Distribution of the Even Number in $5 \times 3$ Across 
Table 3. The Calculated Result

\begin{tabular}{cccc}
\hline span & $\begin{array}{c}\text { Standardize the load effect } \\
\text { of maximum bending } \\
\text { moment }(\mathrm{KN} \cdot \mathrm{m})\end{array}$ & $\begin{array}{c}\text { The actual load effects of } \\
\text { maximum bending } \\
\text { moment }(\mathrm{KN} \cdot \mathrm{m})\end{array}$ & Ratio \\
\hline 10m simply support & 631.25 & 742.95 & 1.18 \\
15m simply support & 1120.31 & 1309.71 & 1.17 \\
20m simply support & 1725.00 & 2081.72 & 1.21 \\
25m simply support & 2445.31 & 3054.73 & 1.25 \\
30m simply support & 3281.25 & 4164.73 & 1.27 \\
35m simply support & 4232.81 & 5408.14 & 1.28 \\
40m simply support & 5300.00 & 6669.99 & 1.26 \\
50m simply support & 7781.25 & 9729.23 & 1.25 \\
5×30m odd cross & 2610.00 & 3231.15 & 1.24 \\
$5 \times 30 m$ even cross & 2197.00 & 2691.50 & 1.23 \\
\hline
\end{tabular}

The bridges listed in this article have strong representative as they are widely used in practical engineering. By comparing the results, you can know the actual running automobile load and regulate highway - grade I load the maximum bending moment ratio of between 1.17 and 1.28, shows that the norms of vehicle overloading load than in some important transportation highway line operation of vehicle load is small during this period. Due to the low design load standard of the bridge, although the impact is not obvious in a short period of time after the completion of the bridge ${ }^{[16]}$, then under heavy load caused by the overload vehicles for a long time, the highway bridges will highlight the significant problems such as damage, even may cause bridge accidents.

\section{Conclusion}

1. Depending on the different number of axle, overloading vehicles can be classified into five types, such as two-axle car, three-axle, four-axle, five-axle and six-axle, then studying for equivalent wheelbase and the axle load of each model. Analysis of the vehicle spacing which obey the lognormal distribution, and simulates the related formula.

2. Comparing with the lane load bending effect according to the first level in the highway code, the actual vehicle load is higher, so load improvement factor is proposed. If the span is less than $20 \mathrm{~m}$, then use 1.2 times the standard specification in bridge design; in other situation, use 1.3 times the standard factor.

Due to the influence of objective condition, this paper gets some useful conclusions, but there are some deficiencies, there are still in need of improvement and further research work, for example the vehicle load characteristics are different according to different regions and seasons. This paper only carried on the actual investigation of traffic load in Hebei province, so the conclusion is applicable to the design of highway bridges in this place. Next to make it is possible to establish vehicle load spectrum that can applied in the whole country. When the actual vehicle load loading on the bridge, the impact of the bridge will also be different as the lane position of axle load changes from time to time. Because of the influence of the objective factors, in order to simplify the calculation process, the paper does not consider the vehicle load under different lanes distribution, so it can be further studied about the effect that overloading vehicles in different lanes of the bridge 


\section{References}

[1] Issued by the Ministry of Communications, the Ministry of Police, Develop and Reform Committee, Quality Survey General Bureau, Safety Survey Administration Bureau, Industrial and Commercial Bureau, Legal System Office. Enforcement Program on Administer the Vehicle with Overload or Overlimited in Whole Country [Z].Beijing. (2004).

[2] General Code for Design of Highway Bridges and Culverts. JTG D60, (2004).

[3] Cai Jiaming. Better Fitting for Distribution of Vehicles Flow on Road Segment of City [J]. Journal of shanghai university of engineering science, (2006), 20(2) :100-103.

[4] Wang Shuo. Study On Load Condition for In-service Bridge [D].Shanghai: Tongji University, (2007).

[5] Chen Min, Li Li, Yue Feng, Ren Xiaosong. Analysis of WIM Data for Fatigue Loading Study of Highway Bridges [C]. Proceedings of the Seventeen National Conference On Structural Engineering. No.II. (2008).

[6] Guo Tong, Li Aiqun, Zhao Daliang. Multiple-peaked probabilistic vehicle load model for highway bridge reliability assessment [J]. Journal of Southeast University(Natural Science Edition), (2008), 38(5): 763-766.

[7] Gindy M. Development of a reliability-based deflection limit state for steel girder bridges[D]. Rutgers University, (2004)

[8] O'connor A, O'Brien E J. Traffic load modelling and factors influencing the accuracy of predicted extremes [J]. Canadian Journal of Civil Engineering, (2005), 32(1): 270-278.

[9] Wang Zhongwei. The Development History of the Vehicle Load Standard in Our Country's Road and Bridge Design Regulations [J]. Standardization of traffic, (2005),12:32-34.

[10] Vrouwenvelder A, Waarts P H. Traffic loads on bridges [J]. Structural Engineering International, (1993), 3(3): 169-177.

[11] Mei Gang, Qin Quan, Lin Daojin. Bi-modal probabilistic model of highway and bridge vehicle loads [J]. J Tsingh ua Univ ( Sci \& Tech ), (2003), 43(10): 1394-1396.

[12] Nowak A S. Live load model for highway bridges [J]. Structural Safety, (1993), 13(1): 53-66.

[13] Zhou Yongtao, Zhai Hui, Bao Weigang, Liu Yanfang. Research on Standard Fatigue Vehicular Load for Highway Bridges [J]. Highway, (2009), (12):21-25.

[13] Tang Guangwu, Liao Jingbo, ZhaoYan, Guo Qian. Research Advance of Assessment Theory for Bridge Structure Based on Influence Line [J]. Technology of Highway and Transport, (2008), (6) :39-43.

[14] Li Z X, Chan T HT, Zheng R. Statistical analysis of online strain response and its application in fatigue assessment of a long-span steel bridge [J]. Engineering structures, (2003), 25(14) :1731-1741.

[15] Sieniawska R, Sniady P. Life expectancy of highway bridges due to traffic load [J]. Journal of Sound and Vibration, (1990), pp. 31-38.

\section{Authors}

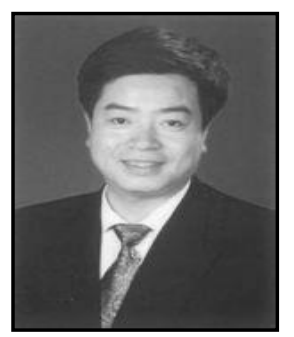

Dou Yuanmimng, He was born in 1956. Now he is a Professor and PhDsupervisor in the School of Civil Engineering, Hebei University of Technology, Tianjin. Also he is the commissioner of State-owned Assets. He obtained his $\mathrm{PhD}$ in civil Engineering from the TIANJIN University in 2002.His research work has centered on teaching and researching on building materials and structural engineering.

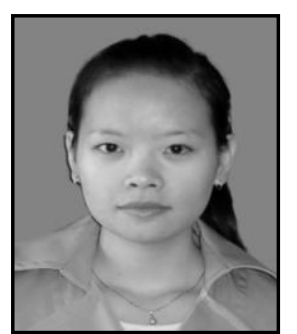

Zhang Jingjing, She was born in 1990, Hebei province. She is a $\mathrm{PhD}$ student in Hebei university of Technology, Tianjin. That is a continuous academic project that involves postgraduate and doctoral study. She has studied there for 7 years. Her major research is the remaining service life of the bridge structure. 


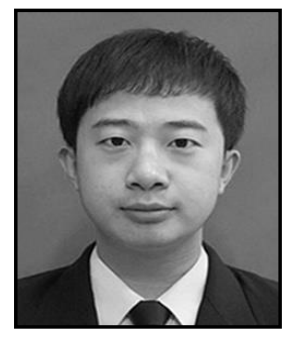

Hu Chao, He was born in 1989, Hebei province. He just graduated from Hebei university of Technology in Jan.2015. He was also a master student of Hebei University of Technology, and got his master degree in 2011. His major research is bridge structure stability. 